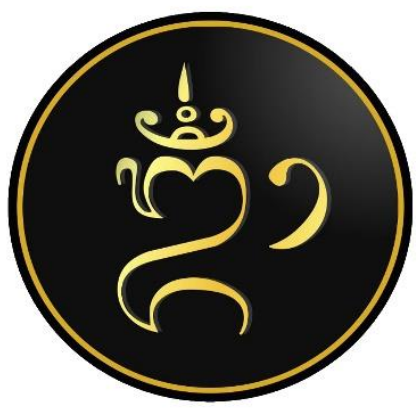

E-ISSN: $2722-8576$

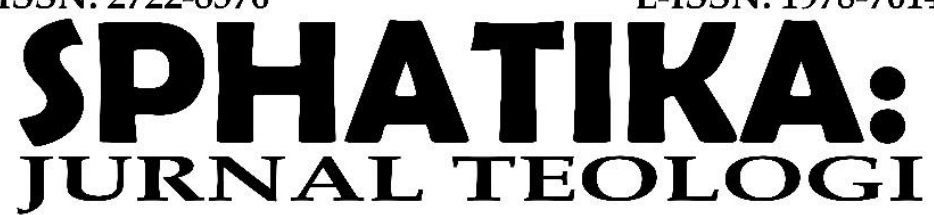

UNIVERSITAS HINDU NEGERI

I GUSTI BAGUS SUGRIWA DENPASAR

VOLUME 12 NOMOR 1, MARET 2021

\title{
KAJIAN FILOSOFI DAN AKTUALISASI AJARAN BHAKTI YOGA
}

\author{
Ngakan Ketut Juni' ${ }^{1}$ I Made Adi Brahman ${ }^{2}$ \\ 1,2Universitas Hindu Negeri I Gusti Bagus Sugriwa Denpasar \\ ${ }^{1}$ ngakanketutjuni@gmail.com
}

Keywords: adoration; bhakti yoga; compassion
Kata kunci:

bhakti yoga; kasih saying; pemujaan
Abstract (Justify, Italic and Bold, book antiqua 11)

The teaching of bhakti yoga is a teaching that examines how or how to connect and unite with God. Bhakti yoga emphasizes the path of developing deep compassion, reverence, service and devotion towards God in all His manifestations. The teaching of bhakti yoga is expressed in several ways, including: carrying out prayers / worship, having a heart full of gratitude, respecting anyone, and carrying out social activities.

Abstrak (rata kanan kiri, cetak miring dan tebal, book antiqua 11)

Ajaran bhakti yoga merupakan salah satu ajaran yang mengkaji tentang cara atau jalan menghubungkan dan menyatukan diri dengan Tuhan. Bhakti yoga menekankan pada jalan pengembangan rasa kasih sayang, penghormatan, pelayanan, dan pengabdian secara mendalam yang ditujukan kepada Tuhan dengan segala manifestasiNya. Ajaran bhakti yoga ini diungkapkan dengan beberapa cara antara lain: melaksanakan persembahyangan/pemujaan, memiliki hati penuh dengan rasa syukur, hormat dengan siapapun, dan melaksanakan kegiatan sosial.

\section{PENDAHULUAN}

Sebagai mahluk religius, manusia tidak dapat melepaskan dirinya dari keyakinan tentang keberadaan Tuhan sebagai asal mula dan tempat kembalinya semua bentuk kehidupan. Sifat dan nilai kerohanian yang ada dalam diri manusia menjadikan manusia sebagai mahluk yang paling mulia dibandingkan dengan mahluk hidup 
lainnya. Selain itu manusia juga mampu memuliakan mahluk yang lainnya karena adanya sifat kerohanian yang bersemayam dalam dirinya. Sifat kerohanian yang bersemayam dalam diri manusia mesti dibangunkan agar hidup manusia menjadi lebih mulia dan lebih mengenal hakikat sang diri sejati yang ada dalam diri.

Berbagai macam cara dan upaya dapat dilakukan oleh umat manusia untuk mengasah dan membangkitkan aspek kerohanian yang ada dalam diri serta mendekatkan diri kehadapan Tuhan. Diantara berbagai cara yang dapat ditempuh tersebut, salah satunya adalah melalui pelaksanaan bhakti yoga. Bhakti yoga merupakan upaya mendekatkan diri kehadapan Tuhan melalui pelaksanaan dan pengembangan rasa bhakti secara lebih luas dan mendalam.

Kebutuhan akan rasa bhakti merupakan kebutuhan alami yang ada dalam diri manusia. Seperti halnya badan yang membutuhkan makanan untuk dia berkembang, demikian juga rohani manusia membutuhkan curahan bhakti yang lebih luas dan mendalam agar ia mampu untuk lebih mengembangkan sifat-sifat kerohanian yang ada dalam dirinya. Adalah kerena adanya rasa bhakti yang mendorong manusia untuk melakukan tindakan-tindakan yang mulia. Berikut akan dibahas filosofi dan implementasi ajaran bhakti dalam kehidupan masyarakat.

\section{METODE}

Jenis dan pendekatan dalam penelitian ini menggunakan metode kualitatif. Jenis dan sumber data yang digunakan adalah kualitatif dan sumber data yang digunakan berupa data primer dan data sekunder. Teknik pengumpulan data yang digunakan seperti studi kepustakaan dan studi dokumen. Teknik analisis data dilakukan dengan beberapa tahapan seperti reduksi, penyajian data dan verifikasi penyimpulan. Teknik penyajian analisis data dilakukan dengan metode deskriptif kualitatif.

\section{PEMBAHASAN}

\section{Ajaran Bhakti Yoga}

Bhakti yoga merupakan salah satu bagian dari yoga yang menekankan pencarian kepada Tuhan melalui mengembangkan rasa bhakti (kebhaktian) kehadapan Tuhan atau Ida Sang Hyang Widhi Wasa. Rasa bhakti ini tidak hanya ditujukan kehadapan Beliau, namun secara lebih luas lagi ditujukan kepada segala mahluk ciptaanNya yang di alam semesta ini. Seorang bhakta dengan penuh kesadaran mengembangkan rasa bhakti ini demi bhaktinya yang mendalam kehadapan Beliau. 
Bhakti Yoga adalah ilmu tentang tingkatan kasih yang lebih tinggi. Ia menunjukkan kepada kita bagaimana cara mengarahkannya, menunjukan bagaimana mengendalikannya, bagaimana mengaturnya, bagaimana menggunakannya, bagaimana memberi tujuan. Dari semua itu hasil yang paling tinggi dan teragung adalah spiritual. Bhakti Yoga tidak mengatakan, "Menyerahlah", namun hanya berkata :"Kasihi; kasihi yang Tertinggi!" dan segala yang rendah berjatuhan, objek yang kasihnya adalah yang tertinggi (Vivekananda, 2008 : 56). Sejalan dengan pengertian di atas, menurut Sivananda (2000: 135) dinyatakan bahwa bhakti merupakan kasih sayang yang mendalam kepada Tuhan, yang merupakan jalan kepatuhan atau bhakti.

Berdasarkan uraian tersebut di atas, bhakti yoga merupakan metode atau cara menghubungkan dan menyatukan diri dengan Tuhan melalui pendalaman dan pengembangan rasa bhakti kehadapan Tuhan dengan segala mahluk ciptaanNya. Rasa bhakti atau kebhaktian yang mendalam kehadapanNya, dapat dilakukan dengan mengembangkan rasa cinta kasih, hormat, pelayanan, pengabadian dan persaudaraan kehadapan semua mahluk. Dengan mengembangkan rasa bhakti yang ada dalam diri, seseorang bhakta berusaha untuk menekan sifat-sifat keegoannya yang selama ini menutupi cahaya cinta kasih dan kemuliaan yang bersemayam dalam diri.

\section{Aktualisasi ajaran Bhakti Yoga}

Rasa bhakti merupakan warisan berharga dari Tuhan yang diberikan kepada umat manusia. Rasa bhakti ini adalah perwujudan yang sangat dalam dan halus dari cinta kasih Tuhan kepada umat manusia. Dengan mengembangkan rasa bhakti ini hingga pada tingkatannya yang tertinggi, maka segala anugrah dan cinta kasih Tuhan akan dengan sangat mudah untuk didapati. Dengan bekal rasa bhakti yang mendalam, kehidupan manusia di dunia fana ini akan dapat dijalani dengan lebih harmonis, damai, tentram dan bahagia. Ibaratnya seorang anak yang memiliki rasa bhakti yang begitu mendalam dan tulus kepada orang tuanya, maka dengan senang hati dan penuh kasih sayang, orang tua tersebut akan memberikan segala kemuliaan dan anugrah yang ia miliki kepada anak-anaknya yang terkasih.

Ajaran bhakti yoga yang begitu luhur nilainya hanya akan menjadi sebuah wacana kalau tidak diaktualisasikan di dalam dinamika kehidupan sehari-harinya. Dan, semua itu tidak akan mampu membawa peradaban umat manusia menjadi lebih baik dan mulia. Untuk itu nilai-nilai luhur yang terkandung di dalam ajaran bhakti yoga ini hendaknya diaktualisasikan dan dijadikan pegangan serta tuntunan dalam menjalani 
dinamika kehidupan, sehingga kehidupan ini menjadi lebih bernilai dan lebih mulia yang setara dengan kehidupan para dewa-dewa di sorga. Harapannya tentu nilai luhur dan mulia dari ajaran ini akan dapat membawa kehidupan di dunia ini menjadi lebih baik, mulia, damai, tentram dan bahagia.

\subsection{Sembahyang Sebagai Wujud Rasa Bhakti}

Bersembahyang secara sungguh-sungguh merupakan salah satu ciri orang yang menjalankan atau mengamalkan ajaran agama. Sembahyang merupakan sebuah kegiatan yang tidak dapat dilepaskan dari kehidupan beragama karena dalam melakukan persembahyangan inilah terjadi hubungan atau komunikasi batin antara manusia dengan Tuhan yang dipujanya. Semakin sering seseorang melaksanakan persembahyangan secara mendalam dengan penuh rasa kebhaktian, maka semakin dekat pula terjadi hubungan batin antara umat dengan Tuhannya. Lambat laun kedekatan hubungan batin yang terjalin antara umat dengan Tuhannya akan berdampak pada timbulnya rasa kedamaian, kebahagiaan, dan keseimbangan batin dalam diri pemuja.

Sembahyang atau pemujaan terhadap Tuhan adalah salah satu perwujudan dari rasa bhakti. Pengertian bhakti lebih luas dari sembahyang, dan sembahyang sendiri merupakan salah satu wujud dari ungkapan rasa bhakti. Tujuan sembahyang untuk melatih diri agar struktur alam pikiran menjadi kuat. Agar kesadaran budhi menjadi lebih kuat menguasai kadar kecerdasan pikiran dan pikiran menguasai ego, maka tri guna haruslah diolah dengan baik (Wiana, 2007: 14). Dengan melaksanakan rutinitas persembahyangan secara tekun dan mendalam secara tidak sadar struktur alam pikiran akan dibentuk semakin halus, suci, murni dan penuh dengan kekuatan cinta kasih Tuhan. Seseorang bhakta yang struktur pikiran yang telah diisi penuh dengan kekuatan suci dari cinta kasih Tuhan yang didapat dari melaksanakan sembahyang, maka budhinya menjadi semakin halus, dan tabah dalam menghadapi segala permasalahan hidup. Dengan demikian tujuan dari sembahyang telah dapat dicapai oleh mereka yang memiliki sifat-sifat tabah, sabar, penuh ketulusan, dan seimbang dalam menghadapi permasalahan hidup.

Seperti halnya orang yang merasakan jatuh cinta maka setiap saat rasanya dia ingin mengunjungi kekasihnya, dia rindu untuk bertemu menyampaikan rasa hatinya. Dalam konteks kehidupan beragama, keinginan untuk bertemu dengan Tuhan sebagai kekasih hati yang termulia itu diwujudkan dengan sembahyang. Demikianlah orang 
yang sudah tergetar dengan cinta (bhakti) kepada Tuhan akan melaksanakan sembahyang dengan taat, dan setiap saat sembahyang dia merasakan kerinduan dan kedamaian yang begitu mendalam. Suatu kerinduan kepada Tuhan yang datangnya dari lubuk hati terdalam. Ketika seseorang benar-benar telah merasakan kerinduan yang terdalam atau merasakan "kegilaan" pada Tuhan, disanalah rasa bhakti yang sesungguhnya telah tumbuh dan berkembang dalam dirinya.

\subsection{Sikap Bersyukur Cerminan dari Rasa Bhakti}

Rasa bhakti kehadapan Tuhan juga dapat diwujudkan atau dinyatakan dengan senantiasa memanjatkan rasa bersyukur kehadapan Tuhan atas segala sesuatu yang telah Beliau berikan baik itu sesuatu yang menyenangkan ataupun yang menyedihkan. Segala cobaan atau permasalah yang timbul akibat dari adanya hubungan dengan benda-benda duniawi, pada dasarnya memiliki suatu tujuan yaitu untuk membersihkan segala karma-karma buruk dari kelahiran dan menjadikan seseorang menjadi semakin bersih dan suci. Namun, mereka yang tidak dapat memahami dan sadar akan hal tersebut cenderung bersikap putus asa dan selanjutnya akan tenggelam ke dalam lautan penderitaan. Akan tetapi bagi mereka yang memahami bahwa segala penderitaan yang timbul dalam kehidupan ini adalah suatu proses pembersihan karma buruk, maka dengan penuh kesadaran dan kesabaran mereka akan bergulat dengan penuh rasa optimisme menghadapi semuanya dengan hati penuh rasa ketabahan.

Rasa suka dan duka adalah seperti riaknya lautan yang datang silih berganti. Nikmatilah semuanya ini dengan tabah, dan rasa syukur. Orang yang bisa bersyukur dalam keadaan yang paling menyedihkanpun adalah orang yang optimis. Optimis adalah dasar dari kekuatan hidup (Cudamani, 1990: 43). Orang yang bisa bersyukur adalah orang yang sudah dapat menundukkan egonya, orang yang rendah hati dan penuh iman. Sikap optimisme yang berakar dari sikap bersyukur merupakan suatu kekuatan yang dasyat untuk menghadapi permasalahan kehidupan.

Perasaan bersyukur merupakan cerminan dari seseorang yang berjiwa besar. Bagimanapun keadaan yang sedang dihadapi, sikap dan rasa bersyukur hendaknya senantiasa dipanjatkan di dalam hati dan dicermikan di dalam setiap tindakan karena seseorang yang mampu mensyukuri apa yang telah Tuhan gariskan dalam kehidupannya adalah anugrah yang terbaik dari Tuhan.

Sikap tabah, sabar dan penuh rasa bersyukur dalam menghadapi setiap permasalahan kehidupan merupakan kekuatan untuk memenangkan pergulatan hidup 
ini. Tujuan dari pergulatan hidup ini adalah kemenangan melawan semua cobaancobaan hidup seperti penderitaan, penyakit, kebodohan, dan semua kemelekatan yang ditimbulkan oleh adanya hubungan dengan dunia maya ini. Mereka yang senantiasa memiliki sikap sabar, teguh dan penuh rasa bersyukur serta berpegang teguh pada ajaran dharma dalam menghadapi cobaan-cobaan dalam hidup ini adalah mereka yang pantas untuk memperoleh kebahagiaan.

Hukum dunia menyiratkan bahwa tidak ada sesuatu yang berharga atau yang memiliki nilai tinggi dapat diperoleh dengan mudah. Demikian juga untuk mendapatkan kebahagiaan di dalam Tuhan diperlukan perjuangan yang tidak mengenal putus asa, bertekat kuat seperti baja, tidak pantang menyerah, dan sikap yang sabar. Tuhanpun tidak dengan mudah memberikan kebahagiaan itu tanpa terlebih dahulu menguji kesungguhan hati umatnya. Hanya pada mereka yang datang dengan segala kerendahan hati, penuh kesabaran, tidak egois, tetap teguh dalam pengendalian diri, penuh rasa berbhakti dan senantiasa memiliki rasa bersyukur atas segala yang telah Tuhan berikan padanya, maka Tuhan akan menyambut mereka dalam dekapan kasih sayang yang penuh dengan kehangatan dan kebahagiaan.

\subsection{Mengembangkan Sikap Hormat dan Cinta Kasih kepada Semua Mahluk Hidup}

Tuhan adalah asal mula dan tempat berakhirnya semua kehidupan yang ada di seluruh semesta raya ini. Tuhan meresapi dan berada di dalam setiap mahluk dan benda yang telah Beliau ciptakan, dan sekaligus Beliaupun berada di luar dari ciptaaNya tersebut. Kehidupan di dunia ini tidak ubahnya seperti sebuah ikatan dalam suatu keluarga besar, dan kenyataanya memanglah demikian karena segala sesuatunya berasal atau bersumber dari Tuhan itu sendiri. Dalam hal ini Tuhan tidak ubahnya seperti orang tua yang melahirkan dan merawat anak-anaknya. Semua mahluk hidup adalah anak-anak Tuhan yang memiliki hak dan kewajiban yang sama terhadap dan dihadapanNya. Di mata Tuhan tidak ada perbedaan status tinggi atau rendah, besar atau kecil, mulia atau hina, namun semua anak-anak beliau dipandang memiliki kedudukan yang sama.

Anak yang memiliki rasa bhakti terhadap orang tuanya adalah seorang anak yang mampu menunjukkan rasa hormat, memberikan pelayanan, cinta kasih, dan mampu menghadirkan rasa bahagia bagi orang tuanya, meskipun orang tua tidak memintanya secara langsung. Anak yang berbhakti adalah anak yang paham dan mampu untuk melaksanakan kewajibannya tersebut. Demikian juga sebagai umat manusia yang pada 
dasarnya adalah juga sebagai anak-anaknya Tuhan memiliki kewajiban untuk berbhakti kehadapanNya.

Berbekal dari rasa bhakti kehadapan Tuhan Yang Maha Esa sebagai orang tua dari kehidupan keluarga besar di dunia ini, kembangkanlah rasa cinta kasih, saling hormat menghormati, tidak mementingkan diri sendiri, saling pengertian, toleransi, dan bhakti kepada sesama saudara umat manusia dan mahluk hidup lainnya sebagai cerminan rasa bhakti manusia terhadap Tuhan. Mereka yang mampu melaksanakan hal tersebut adalah anak-anak Tuhan yang terkasih, karena mereka mampu memberikan rasa bahagia dan mampu menunjukkan rasa bhaktinya kehadapan Tuhan Yang Maha Esa sebagai Bapak dan Ibunya seluruh mahluk hidup dan yang memberikan kehidupan.

\subsection{Aktualisasi Ajaran Bhakti Yoga dalam wujud Kegiatan Sosial}

Pada prinsipnya kegiatan sosial merupakan perwujudan nyata dari rasa bhakti kehadapan Tuhan Yang Maha Esa. Kehidupan manusia tidak dapat dilepaskan dari dua aspek dasar yaitu selaku mahluk pribadi dan mahluk sosial. Selaku mahluk sosial, kehidupan manusia yang satu tidak dapat dilepaskan dari kehidupan manusia yang lainnya, baik dari segi kepentingan, kebutuhan maupun aspek sosial lainnya. Aspek sosial ini tercipta dari adanya ikatan emosional yang menyatukan antara satu individu dengan individu yang lainnya, yang dari sudut pandang agama bahwa pada dasarnya setiap individu dihidupkan oleh Jiwa atau Roh yang tunggal. Maka tak heran kalau ada suatu bencana atau penderitaan yang menimpa salah satu individu, kelompok atau juga suatu bangsa, maka hal tersebut juga dapat dirasakan oleh individu, kelompok atau juga bangsa yang lainnya. Bahkan mereka rela memberikan bantuan baik berupa materi maupun dorongan semangat atau doa-doa pada mereka yang sedang mendapatkan penderitaan.

Melaksanakan kegiatan sosial dengan memberikan bantuan kepada mereka yang terkena musibah atau lagi mengalami penderitaan, merupakan salah satu wujud pelaksanaan yadnya atau korban suci, yaitu manusa yadnya. Manusa yadnya atau korban suci yang ditujukan kepada manusia merupakan salah satu wujud rasa bhakti kehadapan Tuhan Yang Maha Esa, dan yadnya inipun secara kualitas tidak ada perbedaan dari yadnya disuguhkan kehadapan para dewa, leluhur, pendeta dan juga para butha. Dan bahkan menurut beberapa kalangan yadnya yang diberikan kepada sesama manusia malampaui yadnya yang lainnya, seperti yang dinyatakan oleh Donder berikut ini. "Secara universal yadnya atau korban suci kepada umat manusia 
sesungguhnya melampaui segala yadnya sebab memberikan sesuatu kepada sesama umat manusia sama artinya dengan menghaturkan kepada Tuhan" (Donder, 2006: 341).

Melaksanakan tugas sebagai bentuk persembahan kepadaNya. Menyadari kehadiran Tuhan sehingga kita tidak tersesat dari jalan kebenaran. Kehadiran Tuhan akan memberikan inspirasi bagi kita untuk melaksanakan tugas, sehingga ada manfaat yang dipersembahkan. Kerja kita akan menjadi persembahan (Murthy, 2009: 18-19). Banyak macam cara yang dapat ditempuh dalam mewujudkan rasa bhakti kehadapan Tuhan Yang Maha Esa, dan salah satunya dengan secara ringan tangan dan didorang oleh perasaan yang tulus dan iklas, membantu saudara-saudara umat manusia atau mahluk hidup yang lainnya yang sedang dilanda penderitaan. Melaksanakan kegiatan sosial dengan landasan bahwa apa yang dilakukan sebagai bentuk persembahan kehadapan Tuhan merupakan bentuk dari yadnya yang bebuah kemuliaan. Seorang bhakta yang mampu menjadikan setiap tindakan yang ia lakoni sebagai bentuk persembahan merupakan kualifikasi seorang bhakta yang dicintai oleh Tuhan itu sendiri.

\section{PENUTUP}

Bhakti yoga merupakan salah satu ajaran untuk mengantarkan umat manusia menuju pada Tuhan sebagai asal mula dan berakhirnya segala kehidupan. Bhakti yoga merupakan jalan untuk menghubungkan diri dengan jalan mengembangkan rasa cinta kasih, pengendalian diri, tidak mementingkan diri sendiri, bersikap seimbang antara suka dan duka, tidak bersikap egois, senantiasa melakukan pemujaan terhadap Tuhan, tekun dalam meditasi dan memiliki keyakinan yang teguh dan kokoh kuat kepada Tuhan. Jalan bhakti adalah jalan yang sangat alamiah, sederhana, dan relatif lebih mudah yang dapat ditempuh oleh semua orang dari latar pendidikan apapun. Semangat dan rasa bhakti kehadapan Tuhan tidak akan banyak faedahnya kalau tidak diaktulisasikan atau dijadikan laku dalam kehidupan sehari-hari. Bhakti yoga dapat diaktualisasikan dengan cara melaksanakan persembahyangan atau pemujaan terhadap Tuhan dengan segala manifestasinya. Selain itu bhakti ini juga diwujudkan dengan cara lain seperti mengembangkan rasa bersyukur sebagai cerminan rasa bhakti, mengembangkan sikap hormat dan cinta kasih kepada sesama mahluk hidup, dan melaksanakan kegiatan sosial sebagai bentuk perwujudan rasa bhakti kehadapan Tuhan Yang Maha Esa. 


\section{DAFTAR PUSTAKA}

Cudamani, 1990. Pengantar Agama Hindu Untuk Perguruan Tinggi. Jakarta: Yayasan Dharma Saratih.

Donder, I Ketut, 2006. Brahmavidya : Teologi Kasih Semesta. Surabaya: Paramita.

Jendra, I W, 2005. Tuhan Sudah Mati? Untuk Apa Sembahyang. Surabaya: Paramita.

Murthy, M.V.N. 2009. Siapa Bhakta Bagi Sai Baba. Denpasar: Cakepan.

Pudja, G., 2004. Bhagawadgita. Surabaya: Paramita.

Sivananda, Swami, 2003. Intisari Ajaran Hindu. Surabaya: Paramita.

Tim Penyusun, 2005. Siwatattwa. Denpasar: Pemerintah Propinsi Bali.

Vivekananda, Swami, 1991. Karma Marga. Terjemahan Yogamurti MR. Jakarta: Hanuman Sakti.

Vivekananda, Swami, 2008. Bhakti Yoga (Terj. IGA Dewi Paramita, S.S). Surabaya: Paramita.

Wiana, I Ketut, 2007. Sembahyang Memuja Tuhan dengan Sembilan Bentuk Bhakti. Denpasar: Panakom. 